\title{
Hacia una ciencia de los derechos humanos
}

\author{
Cristina Fuertes-Planas Aleix \\ Universidad Complutense de Madrid \\ cfuertes@ucm.es
}

\begin{abstract}
Resumen:
Preguntarse acerca de la posibilidad de una ciencia de los derechos humanos no constituye una cuestión superficial. Por el contrario, significa la posibilidad de abordar un estudio metódico, sistematizado, un seguimiento a través de su historia, instituciones, garantías, medios de protección. Una jerarquización de los mismos, posibilidades de implementación en el mundo. La creación de un ethos y una cultura de los derechos humanos. No es una misión fácil, choca con multitud de dificultades ya que su definición es difícil, su objeto es incierto e inseguro y sobre él convergen múltiples disciplinas, su metodología no es única, sino múltiple. No obstante, merece la pena intentarlo, sobre todo para lograr su mejor difusión y para conseguir su afianzamiento precisamente en un momento como el actual en el que múltiple peligros estructurales, políticos, económicos e ideológicos amenazan con destruir las conquistas conseguidas lentamente a lo largo de décadas.
\end{abstract}

Palabras clave: Ciencia; derechos humanos; método; cultura.

\section{Toward a Science of Human Rights}

\begin{abstract}
:
To ask oneself about the possibility of a science of human rights does not constitute a superficial question. Contrariwise, it means the possibility of discovering a methodical study, systematic, a tracking through the length of its history, institutions, guarantees, means of protection, a hierarchy of the same, the possibility of implementation worldwide, the creation of an ethos and a culture of human rights. It is not an easy mission, and clashes with numerous difficulties since its definition is ambiguous, its goal uncertain and unsure, and upon it converge many disciplines; its methodology is not unique but rather multifaceted. Nevertheless, the attempt is worthwhile, particularly to obtain its better dissemination and acceptance, particularly at a moment like the present when multiple structural, political, economic and ideological dangers threaten to destroy the victories obtained gradually over the passage of the decades.
\end{abstract}

Key Words: Science; human rights; method; culture.

\section{Referencia normalizada:}

Fuertes-Planas Aleix, C. (2014): Hacia una ciencia de los derechos humanos. Historia y Comunicación Social. Vol. 19. Núm. Especial Enero. Págs. 221-233.

SUMARIO: 1- Introducción; 2- Problemas ante un estudio científico de los derechos humanos; 3- ¿Qué entendemos por ciencia de los derechos humanos?: 3.1 Objeto de estudio; 3.2 Método de estudio; 3.3 ) Ciencia independiente; 3.4) Temas de estudio; 3.5) Clasificaciones: 3.5.1 Clasificaciones doctrinales; 3.5.2 Clasificaciones normativas positivas; 3.6) Jerarquización de los derechos humanos: 3.6.1 Con carácter previo y como presupuesto de los restantes derechos y libertades, se encontrarían aquéllos que tutelan la vida y la integridad física y moral del hombre del hombre; 3.6.2 Derechos de libertad, derecho a la vida privada, libertad de pensamiento, derecho a la igualdad y derechos de la mujer y de las minorías; 3.6.3. Derecho al progreso social y a la felicidad; 3.6.4. Derecho a una justicia imparcial; 3.6.5. Libertad de expresión y derecho a estar informado; 3.6.6. Derecho de acceso al poder decisorio por mediación de los partidos políticos y del sufragio universal y derecho a formar grupos de presión 
para formular sus demandas específicas; 4- Los derechos humanos como principios jurídicos; 5- Conclusiones; 6- Bibliografía.

\section{Introducción}

El interés por los derechos humanos ha fluctuado a lo largo del tiempo, distinguiéndose claramente al menos dos periodos: el anterior a la corriente iusracionalista en la que no se percibían derechos subjetivos, individuales, sino que lo que destaca en la existencia del derecho objetivo, de la Norma agendi, derecho como conjunto de normas y, por tanto se incide mucho más en las obligaciones que en los derechos que, por otra parte constituyen algo comunitario. La noción de derecho subjetivo o, lo que es lo mismo, la concepción de poseer "mis derechos" -Facultas agendi-, posibilidad de tener ciertas facultades o poderes, conferidas por la existencia del Derecho pero, en todo caso observadas desde el aspecto del sujeto de Derecho -Derecho subjetivo- es muy posterior. Aunque con diversos antecedentes, se constata su aparición con la figura del franciscano Guillermo de Ockham ${ }^{1}$, quien para intentar zanjar la polémica con el Papa Juan XXII, partidario de considerar que los bienes adquiridos por esta orden religiosa eran de su propiedad, lo que contradecía el voto de pobreza contraído, diferencia entre la propietas, que corresponde a la Santa Sede, y el uso de tales bienes. Los franciscanos usaban pero no eran propietarios de los bienes, sólo poseían el usus facti, tenían la potestas, no el poder que confiere la propiedad. Esta primera aproximación a la significación del derecho subjetivo se asienta y perfecciona paulatinamente a lo largo de la historia alcanzando su punto más álgido con la corrientes iusnaturalistas racionalistas de los siglos XVII y XVIII.

A partir de este momento los derechos humanos se van a identificar en gran medida con los derechos subjetivos. La Declaración de derechos del hombre y el ciudadano de 1789, consecuencia de la Revolución Francesa constituye un buen catálogo de este modelo de derechos y libertades erigidas a nivel individual. Aunque con más elementos históricos y religiosos la Declaración de derechos del Buen Pueblo de Virginia de 1776 constituye también una buena prueba de esta ideología.

La evolución posterior de los derechos humanos ha querido superar ese carácter individualista preconizado por el iusracionalismo en busca de una realización práctica más justa y comunitaria, que tuviera en cuenta no sólo al individuo singularmente considerado. Sin embargo, tuvo que pasar un largo periodo de tiempo, padecer desórdenes sociales y revoluciones para dar paso a una nueva visión de justicia social, incorporando los derechos económicos, sociales y culturales, con desigual cumplimiento, atendiendo al espacio geográfico y a la coyuntura económica.

Los periodos posteriores a los grandes enfrentamientos de la Humanidad, de los que el siglo XX constituye un gran espectador son también los de renacimiento,

Villey, M.: La genèse du droit subjetif chez Guillaume d'Ockham, Archives de philosophie du droit, 1964, pág., 98. 
re-creación de los derechos humanos. El periodo que sigue a la II Guerra Mundial es fiel testigo de esta realidad. Se produce un consenso casi universal que se plasma en la Declaración Universal de Derechos Humanos de la ONU, en 1948. De este momento histórico existe abundante bibliografía que corrobora el re-surgir del derecho natural, que se manifiesta en un conjunto de derechos, libertades, principios al fin que se consideran el contenido de la Justicia.

Desde entonces ha existido una honda preocupación por el estudio estructurado, metódico, sistemático de los derechos humanos con la finalidad de llevar a cabo una mejor protección y transmisión de los mismos, incluso, una externalización. Se trata de una tarea difícil, entramos en un ámbito no ajeno a las ideologías, política, economía, filosofía, derecho. Nos situamos sobre arenas movedizas, en el plano de lo humano y de lo social, de la incertidumbre, de la falta de certeza. ¿Debemos renunciar por ello a un estudio científico sobre los derechos humanos?

\section{Problemas ante un estudio científico de los derechos humanos.}

Los principales problemas para elaborar un estudio científico de los derechos humanos pasan por el concepto mismo que tengamos acerca de lo que constituye o no ciencia. La Jurisprudencia es definida por Ulpiano como "el conocimiento de las cosas divinas y humanas y la ciencia de lo justo y de lo injusto". No había duda, en esta época, de la existencia de un saber científico dotado de gran amplitud. Lo que sucede es que el concepto de ciencia ha ido evolucionando a lo largo del tiempo y su acento principal se centra en el método que se utiliza.

Los derechos humanos, al igual que el propio Derecho y las restantes ciencias humanas plantean el problema de la contingencia y variabilidad de su propio objeto de estudio, así como la pluralidad de factores ideológicos, políticos, económicos, jurídicos, sociales y hasta filosóficos que envuelven, lo que hace extraordinariamente difícil su estudio científico, a menos con una consideración de ciencia en el sentido clásico del término. Por esta razón (refiriéndose a la ciencia del derecho) el jurista alemán von Kirchmann, en 1847 pronunció una conferencia titulada "La falta de valor de la Jurisprudencia como ciencia", en la que negó la posibilidad de la ciencia del derecho, lo que expresó sosteniendo que "la tierra sigue girando alrededor del sol, como hace mil años; los árboles crecen y los animales viven como en tiempo de Plinio. Por tanto, aunque el descubrimiento de las leyes de su naturaleza y su poder haya requerido largos esfuerzos, tales leyes son, por lo menos, tan verdaderas para la actualidad como para los tiempos pasados, y seguirán siéndolo para siempre. Muy otra es la situación de la ciencia jurídica. Cuando ésta tras largos años de esfuerzos, ha logrado encontrar el concepto verdadero, la ley de la institución, hace ya tiempo que el objeto se ha transformado. La ciencia llega siempre tarde en relación con la evolución progresiva; no puede nunca alcanzar la actualidad. Se parece al viajero en el desierto: divisa lejos opulentos jardines, camina todo el día y a la noche están tan 
alejados de él como por la mañana." (...) en "cuanto la ciencia hace de lo contingente su objeto ella misma se hace contingencia: tres palabras rectificadoras del legislador convierten bibliotecas enteras en basura." Ciertamente, este es un concepto muy limitado de ciencia y sólo aplicable a las ciencias de la naturaleza.

En el fondo late la polémica sobre la importancia del objeto de estudio. Bajo el rótulo de ciencia o investigación científica se da a entender que se trata de un estudio riguroso, serio, estable, de resultados previsibles, en el que la ciencia del derecho no tiene cabida. En efecto, la ciencia del derecho no sigue los mismos paradigmas que las ciencias de la naturaleza pero no por ello debemos negar la posibilidad de llevar a cabo un conocimiento útil e importante.

El derecho se centra en fenómenos humanos, de esta realidad deriva su mayor dificultad.

$\mathrm{Si}$, como expresó I. Kant (Crítica de la razón pura) en su época "andan todavía los juristas buscando una definición del derecho", del mismo modo que, mucho más tarde, en 1961, H. L. A. Hart (El concepto de derecho) dedicó toda una obra a esta tarea, el concepto de derechos humanos es aún más complicado si cabe. La ciencia de los derechos humanos tendría como objeto de estudio a estos derechos, es decir, el conjunto de principios o reglas formuladas en las diferentes declaraciones de los derechos del hombre, hayan alcanzado o no una posterior reglamentación, lo que, para mayor dificultad, plantea el problema de si constituyen o no normas jurídicas. En ocasiones aparecen como ideales éticos que deberían cumplirse (¿acaso son simples principios morales?), aunque en muchos casos se encuentran en textos legales y son de obligado cumplimiento. Unas veces se plantean como derechos anteriores a su reconocimiento estatal y de obligatoria protección (doctrina iusnaturalista), otras veces se considera que no existen más derechos que los reconocidos por el estado. La creencia en la existencia de normas anteriores al derecho positivo se ha llegado a considerar doctrinalmente una postura metafísica y una amenaza revolucionaria. ${ }^{3}$

\section{3. ¿Qué entendemos por ciencia de los derechos humanos?}

\subsection{Objeto de estudio}

Atendiendo al objeto, los derechos del hombre serían objeto de estudio simultáneo y complementario (multidisciplinar) de diversas ciencias existentes en la actualidad.

2 Kirchmann, J. H.: La Jurisprudencia no es ciencia, trad., y estudio preliminar A. Truyol Serra. Civitas ( $3^{\text {a }}$ ed.), Madrid, 1983, pág. 16 y 29.

3 Bentham, J.: Analchical Fallacies: being and examination of the Declarations of Rightsissued during the French Revolution, Works ed., Bowring, reimp. De Russell \& Russell, Nueva York, 1962. Esta posición es propia de otros autores positivistas: así J. AUSTIN: The Province of Jurisprudence Determined and the Uses of the Study of Jurisprudence, $3^{\mathrm{a}}$ ed., intr., de H. L. A. Hart, Weindenfeld \& Nicolson, London, 1968, pág., 184. 
Se trataría de un objeto de investigación fragmentado por los diversos conocimientos científicos sistematizados: derecho público y privado, derecho nacional e internacional, derecho administrativo y constitucional, derecho penal y procesal. Los derechos humanos no constituyen únicamente un conjunto de normas legisladas sino que son, sobre todo, una filosofía. Además su estudio, como hemos mencionado es interdisciplinar. Teniendo en cuenta que el modelo riguroso de ciencia se refiere a un solo objeto de conocimiento, su cientificidad sería, cuanto menos, dudosa.

\subsection{Método de estudio}

Resulta difícil también la consideración de un estudio científico que ha de servirse de las diversas metodologías de una diversidad de ciencias: política, historia, derecho, moral, sociología, etc.

\subsection{Ciencia independiente}

Para evitar todos estos inconvenientes se ha considerado la posibilidad de considerar la posible ciencia de los derechos humanos en una ciencia independiente ${ }^{4}$, cuyo planteamiento como ciencia jurídica tendría una diversidad de problemas: a) los derivados de su inserción en una parte especial de alguna de las ramas jurídicas, en cuyo caso sólo podría referirme a derechos positivizados (fundamentales) pero que dejaría fuera aquellos derechos que todavía no se han conseguido alcanzar a nivel estatal y aparecen como ideales (plano moral); b) el mencionado pluralismo en cuanto al objeto de estudio, incompatible con un concepto de ciencia riguroso.

\subsection{Temas de estudio}

Una ciencia de los derechos humanos tiene que contener una dimensión intranacional, es decir, partiendo del ordenamiento jurídico interno, atendiendo a la diversidad de ramas existentes tanto en el ámbito del derecho público como en el de derecho privado y su aspecto internacional, constatando su grado de realización. Comprendería una serie de campos como el concepto, evolución histórica, clases, enfoques en cuanto al objeto de conocimiento, metodología a emplear, procesos de positivación, internacionalización, observación de su cumplimiento, mecanismos de garantía y protección. ${ }^{5}$

Los derechos humanos son objeto de estudio en las facultades de derecho, global o singularmente atendiendo a las ramas jurídicas implicadas; en las facultades de ciencias políticas y también en cursos monográficos. Dado su posible estudio global se incluyen también en el área de la filosofía jurídica.

4 Peces-Barba Martínez, G.: Derechos fundamentales.- Teoría General, Guadiana de publicaciones, 1976, pág., 107, 116 y 117.

5 García Bauer, C.: Este autor presentó esta posibilidad en el VIII Congreso del Instituto Hispano-Luso-Americano de Derecho Internacional. ¿Puede elaborarse ya una disciplina jurídica autónoma de los Derechos Humanos?, en "Veinte años de evolución de los Derechos Humanos", UNAM, México, 1974. 


\subsection{Clasificaciones}

\subsubsection{Clasificaciones doctrinales}

Las clasificaciones de los derechos humanos se plasman en dos planos: a) a nivel doctrinal; b) en el ámbito normativo-positivo. En cualquiera de los dos se han dado múltiples clasificaciones. S. Romano (La teoría de los derechos públicos subjetivos) sostenía, en 1900, a este respecto:

Basta echar una ojeada a las principales distinciones utilizadas por los escritores más eminentes para convencerse de que no hay dos que coincidan entre sí, y las diferencias, nótese bien, no son leves y formales, sino que afectan al modo mismo de concebir el derecho público subjetivo.

Las distinciones doctrinales clásicas comprendían las categorías de derechos civiles (cívicos), derechos políticos y mixtos. Posteriormente se ha aludido a los derechos morales como la dignidad, el honor, la propia imagen, etc. Entrado el siglo XX (aunque con antecedentes en el XIX) se introdujeron los derechos económicos, sociales y culturales, asociados al derecho laboral ${ }^{6}$ (derecho al trabajo, seguridad e higiene, condiciones laborales, riesgos laborales, etc.), así como condiciones de igualdad de oportunidades, distribución de recursos y acceso a la cultura.

En el estado liberal de derecho ${ }^{7}$ del siglo XIX prendió la doctrina, elaborada en Alemania (Gerber, Laband Jellinek), respecto de los derechos públicos subjetivos, ${ }^{8}$ que serían los únicos reconocidos por el Estado, que no coinciden plenamente, al menos formalmente, con el concepto de derechos humanos, ya que estos últimos son más extensos. ${ }^{9}$ Los derechos públicos subjetivos se encuentras garantizados en las Constituciones de los diversos Estados, ${ }^{10}$ mientras que existen muchos derechos humanos que todavía no han sido objeto de positivación.

6 Battaglia, F.: Los derechos del hombre, del ciudadano y del trabajador (esencia, evolución, perspectivas futuras), en "Estudios de teoría del Estado", Publicaciones del Real Colegio de España en Bolonia, Madrid, 1966. A este autor le debemos el término de "derechos sociales del trabajador".

7 Sánchez Agesta, L.: Lecciones de Derecho Político, 6ª edición, Librería Prieto, Granada, 1959.

8 Cascajo Castro, J. L.: Los derechos humanos, significación, estatuto jurídico y sistema. Anales de la Universidad Hispalense, Publicaciones de la Universidad de Sevilla, 1979, pág., 269 y ss. Vid., JELLINEK, G.: Sistema dei diritti pubblici subiettivi, Società Editrice Librería, 1912.

9 M. Hauriou.: Précis de Droit Administratif et de Droit Public, 6 édition, J. B. Sirey, Paris, 1907, pág., 315 señala una diferencia puramente relativa o situacional, entre los "derechos del hombre y del ciudadano" y los "derechos públicos subjetivos": su consideración desde el ángulo de los individuos titulares o desde el régimen jurídico estatal.

${ }^{10}$ Castro de Cid, B.: Dimensión cientifica de los derechos humanos, en "Derechos humanos", pág., 99, nota bibliográfica 99, dice que de hecho, los autores de Derecho Constitucional, sobre todo en la doctrina italiana, no separan de forma tajante ambos conceptos, utilizando los dos términos para designar el mismo contenido. Así, por ejemplo, P. Biscaretti (Derecho Constitucional, Tecnos, Madrid, 1965, pág., 665-713. 
La terminología de libertades públicas, acuñada en el derecho francés, tampoco se correspondería plenamente con el significado más amplio de derechos humanos, ${ }^{11}$ por cuanto las libertades públicas constituyen facultades de los individuos o grupos de individuos, en el ámbito de su autonomía que gozan de la protección estatal.

\subsubsection{Clasificaciones normativas positivas}

En el plano de las clasificaciones intranacionales, durante mucho tiempo las declaraciones y pactos enumeraban los derechos y libertades sin ninguna sistematicidad, incorporando aquellos que estaban vigentes en cada momento histórico. Mucho más adelante comienzan a llevar a cabo clasificaciones con un cierto rigor, como sucede con la Constitución Política de los Estados Unidos Mexicanos (5 febrero 1917), la primera también en incorporar derechos sociales; divide los derechos y obligaciones: De las garantías individuales, de los mejicanos, de los ciudadanos mejicanos, del trabajo y de la previsión social. También la Constitución del Reich Alemán (Constitución de Weimar de 14 de agosto 1919): La persona individual, la vida social, religión y confesiones religiosas, educación y enseñanza, la vida económica. Posteriormente lo harán otras Constituciones, aunque otros textos normativos han continuado con la simple enumeración de derechos.

Por lo que respecta al derecho internacional, se tiende a estructurar los textos positivos de acuerdo a criterios científicos. Hay documentos como la Declaración Universal de Derechos Humanos (1948) o el Convenio para la Salvaguardia de los Derechos del Hombre y de las Libertades Fundamentales (Roma, 4 de noviembre de 1950), que se limitan a enumerar una lista de derechos como inalienables pero sin clasificarlos por grupos. Otros como los Pactos internacionales de 1966 y la Convención Americana sobre Derechos Humanos (San José de Costa Rica, 22 de noviembre de 1969), observan la existencia diferentes tipos de derechos, ya sea señalándolo explícitamente, ya sea estructurando su propio articulado.

\subsection{Jerarquización de los derechos humanos}

Podemos preguntarnos si es posible una jerarquización de los derechos humanos.

3.6.1 Con carácter previo y como presupuesto de los restantes derechos y libertades, se encontrarían aquéllos que tutelan la vida y la integridad fisica y moral del hombre del hombre:

- Derechos que tutelan la vida e integridad física.

- Derecho a la vida e integridad física.

- Derecho a un nivel de vida adecuado y a la protección de la salud.

${ }^{11}$ Duchacek, I. D.: Derechos y libertades en el mundo actual, trad., O. Montserrat, Instituto de Estudios Políticos, Madrid, 1976, pág., 82 y ss., señala, sin embargo, la imposibilidad práctica de separar claramente entre derechos humanos y libertades públicas. 
- Derecho a la seguridad.

- Derecho a la seguridad social, asistencia pública y servicios sociales adecuados.

- Derechos que tutelan la integridad moral:

- Derecho al nombre.

- Derecho a la nacionalidad.

- Derecho al desarrollo de la personalidad y reconocimiento de la personalidad jurídica.

- Derecho a la integridad moral, derecho al honor.

- Derecho a la rectificación.

3.6.2 Derechos de libertad, derecho a la vida privada, libertad de pensamiento, derecho a la igualdad y derechos de la mujer y de las minorías.

- Derecho a no ser sometido a esclavitud.

- Derecho a no ser arbitrariamente detenido o encarcelado.

- Derecho a circular libremente en el territorio nacional o internacional y a elegir residencia.

- Derecho a la igualdad.

- Derecho a la libertad de pensamiento, conciencia, creencia y religión.

- Derecho al respeto y a la intimidad.

- Derecho a la inviolabilidad de domicilio y correspondencia.

- Derecho de los pueblos a la libre determinación del desarrollo social.

- Derecho a la libertad de matrimonio.

3.6.3 Derecho al progreso social y a la felicidad.

- Derecho a la propiedad y a la herencia.

- Derecho al trabajo, libertad de trabajo, retribución justa, seguridad e higiene, aviso previo en caso de cese, protección contra el desempleo, jornada laboral limitada, descanso diario y semanal, vacaciones anuales retribuidas.

- Derecho a seguridad e higiene en el trabajo.

- Derecho a condiciones equitativas de trabajo, participación en beneficios, ascensos, reinstalación e indemnización.

- Derecho a la educación, formación y orientación profesional. 
- Derecho a la conservación y desarrollo de la propia cultura, participación en la vida cultural.

- Derecho a la libertad de comercio y de industria, ejercicio de actividad lucrativa.

- Derecho de los pueblos a promover libremente su desarrollo económico.

- Derecho al ocio.

3.6.4 Derecho a una justicia imparcial.

- Derecho a la protección social, jurídica y económica.

- Derecho de asilo.

- Derecho a ser juzgado y a no ser condenado sin defensa.

- Derecho a que se establezca un orden social e internacional en el que los derechos humanos se hagan plenamente efectivos.

- Derecho a la igualdad y seguridad jurídica.

- Derecho a no ser detenido o arrestado si no es conforme a derecho.

3.6.5 Libertad de expresión y derecho a estar informado.

- Derecho a la libertad de opinión, expresión, comunicación y libertad de culto.

- Derecho a la libertad de información y de prensa.

- Derecho a la libertad de idioma.

- Derecho a la libertad de elección cultural.

- Derecho a la libertad de educar a los hijos.

- Derecho a la libertad de enseñanza.

3.6.6 Derecho de acceso al poder decisorio por mediación de los partidos políticos $y$ del sufragio universal y derecho a formar grupos de presión para formular sus demandas especificas:

- Derecho a la libertad de reunión, asociación y libre determinación.

- Derecho de resistencia.

- Derecho a votar y ser votado, intervenir en el gobierno del país.

- Derecho al tiempo libre para el ejercicio de los derechos políticos.

- Derecho de petición.

- Derecho de defender al país. 
- Derecho de negociación colectiva y de huelga.

- Derecho a colaborar en la gestión.

\section{Los derechos humanos como principios jurídicos}

Vallet de Goytisolo ${ }^{12}$ considera que los derechos humanos son principios constitucionales. Para este autor los derechos fundamentales son los que se encuentran recogidos en el art. 10.2 de la Constitución.

En cuanto a la función jurídica de los principios constitucionales, por lo que respecta a su aspecto intrínseco, los principios actúan incluso en relación con los preceptos de la Constitución, debido a su carácter básico y fundamental, por lo que tienen una primacía interpretativa absoluta sobre los restantes. Son los principios jerárquicamente superiores de todo el ordenamiento jurídico.

En cuanto a su aspecto extrínseco (metodológico) se refiere a la concreción de dichos principios en toda actuación interpretativa y forma parte del tratamiento propio del método interpretativo general. Desde esta perspectiva los jueces y juristas interpretan de acuerdo con su propia disciplina y método, teniendo siempre presente la prioridad de tales principios constitucionales sobre las demás normas integrantes del ordenamiento jurídico positivo, por lo que deben contemplarse como los restantes principios enunciados en las leyes y deben concretarse atendiendo a la realidad viva de que se trate, teniendo en cuenta todas sus circunstancias individualizadoras. ${ }^{13}$

\section{Conclusiones}

René Cassin ${ }^{14}$ ha definido la ciencia de los derechos humanos como:

Una rama particular de las ciencias sociales, que tiene como objeto estudiar las relaciones sociales entre los hombres en función de la dignidad humana, determinando los derechos y las facultades necesarios en conjunto para el desarrollo de la personalidad de cada ser humano

Los derechos humanos, como podemos comprobar, tienen dificultades en cuanto a su inserción como objeto de estudio puramente científico por cuanto constituyen una

12 Vallet de Goytisolo, J- Bms.: ¿Los denominados derechos fundamentales son derechos o son principios jurídicos? Una cuestión lingüística con secuencias jurídicas, Anales de la Real Academia de Jurisprudencia y Legislación, número 36, pág. 13 a 31, Madrid, 2006.

${ }^{13}$ Larenz, K.: Metodología de la ciencia del derecho, trad., Marcelino Rodríguez Molinero, Ariel Derecho, $2^{\mathrm{a}}$ ed., Barcelona, 1980.

${ }^{14}$ Cassin, R.: Amicorum discipolorumque Liber. 4, Méthodologie des droits de l'homme, A. pedone, parís, 1972. 
realidad socio-política y un código ético para evaluar su cumplimiento (una medida sobre la justicia) a nivel internacional.

Sobre todo si partimos de un concepto riguroso de ciencia, es decir, como saber unitario, dotado de un objeto de estudio fijo, a través de una metodología unitaria y específica, como una disciplina autónoma e independiente de otras ciencias.

Esta materia está impregnada de múltiples connotaciones sociales, morales, jurídicas, políticas, ideológicas, además de sus aspectos intra e internacionales.

Se ha atacado doctrinalmente su propia fundamentación, tanto desde ideologías libero-conservadoras (Bentham), por considerarlos peligrosos para la estabilidad social y política; y también desde la perspectiva marxista, en el sentido de considerarlos una práctica burguesa para legitimar las relaciones socio-económicas burguesas, propios de una concepción de la libertad formal y no real, que sólo se produciría cuando se alcanzare la emancipación humana. ${ }^{15}$ También pueden observarse desde la perspectiva iusnaturalista que los considera anteriores al Estado, o positivista para quienes sólo existen los derechos reconocidos por el Estado.

Esta situación nos conduce inevitablemente a un estudio en el que están implicadas una pluralidad de disciplinas: historia, sociología, antropología, derecho, política, cada una de ellas con su punto de vista particular y una metodología específica.

Todos estos aspectos hacen extraordinariamente difícil acometer estudios que hagan prever los resultados e, incluso, poder evaluarlos, así como su repercusión tanto en el ámbito nacional como internacional.

Sin embargo, existen estudios científicos a partir de las diferentes ciencias sociales ${ }^{16}$ cuyos aspectos resultan ineludibles. Es, indiscutiblemente, deseable, un estudio sistemático que comprenda los diversas dimensiones de los derechos humanos, su identificación, evolución, grado de cumplimiento, mecanismos de defensa, su realidad actual, nacional e internacional, los principales problemas en su efectividad, propuestas para su implementación, etc.

No olvidemos, además, los llamados derechos humanos de nueva generación que afrontan situaciones tales como la intimidad en el ámbito de la informática, la protección de los datos personales; el medio ambiente, etc.

Considero que, a pesar de las dificultades, no se debe renunciar al estudio científico de los derechos humanos, eso sí, con un concepto amplio de ciencia, que englobe las diversas perspectivas que nos aportan las ciencias sociales y una pluralidad metodológica.

${ }_{15}$ Marx, K., y Engels, F.: La ideología alemana (1846), Pueblos Unidos-Grijalbo, Montevideo-Barcelona, 1974; El Capital libro I (1867), Siglo XXI, 1978; vid., ATIENZA, M.: Marx y los derechos humanos, Mezquita, Madrid, 1983.

16 Bidart Campos, G. J.: Teoría general de los derechos humanos, Astrea de Alfredo y Ricardo de Palma, Buenos Aires, 1991, pág., 53. 


\section{Bibliografía}

\subsection{Libros:}

ATIENZA, M.: Marx y los derechos humanos, Mezquita, Madrid, 1983

BENTHAM, J.: Analchical Fallacies: being and examination of the Declarations of Rightsissued during the French Revolution, Works ed. Bowring, reimp. De Russell \& Russell, Nueva York, 1962.

BIDART CAMPOS, G. J.: Teoría general de los derechos humanos, Astrea de Alfredo y Ricardo de Palma, Buenos Aires, 1991.

CASCAJO CASTRO, J. L.: Los derechos humanos, significación, estatuto jurídico y sistema, Anales de la Universidad Hispalense, Publicaciones de la Universidad de Sevilla, 1979.

CASTÁN TOBEÑAS, J.: Los Derechos del Hombre, $4^{\mathrm{a}}$ edición actualizada por $\mathrm{M}^{\mathrm{a}} \mathrm{L}$. Marín Castán, Reus, S. A., Madrid, 1992.

CASTRO (DE) CID, B.:

Los derechos humanos. Significación, estatuto jurídico y sistema, Universidad de Sevilla, 1977.

Dimensión científica de los derechos humanos, en AA.VV "Derechos humanos", Publicaciones de la Universidad de Sevilla, 1979, pág. 47 y ss.

HART, H. L. A.: El concepto del Derecho, trad., Genaro R. Carrió, $2^{\mathrm{a}}$ edición, México, Editora Nacional, 1980, del original "The concept of Law", Oxford, Clarendon Press, 1961.

HAURIOU, M.: Précis de Droit Administratif et de Droit Public, $6^{\mathrm{a}}$ édition, J. B. Sirey, Paris, 1907.

JELLINEK, G.: Sistema dei diritti pubblici subiettivi, Società Editrice Librería, 1912.

KANT, I.: Fundamento de la metafísica de las costumbres, traducción A. Rodríguez, Magisterio Español, Madrid, 1977.

MARX, K., y ENGELS, F.:

La ideología alemana (1846), Pueblos Unidos-Grijalbo, Montevideo-Barcelona, 1974.

PECES-BARBA, G.: Derechos fundamentales., I. Teoría General, Guadiana de Publicaciones, Madrid-Barcelona, 1973; la segunda edición es de 1976. La tercera edición es de 1980, publicada en latina Universidad, Madrid.

PÉREZ LUÑO, A. E.:

-Los derechos humanos. Significación, estatuto jurídico y sistema, Publicaciones de la Universidad de Sevilla, 1979.

TRUYOL Y SERRA, A.: Los derechos humanos, Tecnos, Madrid, 1968.

VECCHIO, G.: Los derechos del hombre y el contrato social, trad., M. Castaño, Hijos de Reus editores, Madrid, 1914. 
6.2 Capítulos o artículos en libros o revistas en papel:

BATTAGLIA, F.: Los derechos del hombre, del ciudadano y del trabajador (esencia, evolución, perspectivas futuras), en "Estudios de teoría del Estado", Publicaciones del Real Colegio de España en Bolonia, Madrid, 1966.

HABERMAS, J.: "El concepto de dignidad humana y la utopía realista de los derechos", Dianoia, vol., LV, número 64, (mayo 2010), pág. 3-25.

HART, H. L. A.: ¿Hay derechos naturales?, en "Derecho y Moral. Contribuciones a su análisis", trad., cast., Genaro R. Carrió, Depalma, 1962; ORIGINAL Are there any Natural Rights?, The Philosophical Review, vol., LXIV, $\mathrm{n}^{\circ}$ 2, 1955.

MARITAIN, J.: "Los derechos del hombre. Estudios y comentarios en torno a la nueva Declaración universal", Vol. Colectivo (introducción), UNESCO, 1949.

McKEON, R.: "Las bases filosóficas y las circunstancias materiales de los derechos del hombre", en Los Derechos del Hombre. Estudios y comentarios en torno a la nueva Declaración Universal, Fondo de Cultura Económica, México-Buenos Aires, 1949.

VALLET DE GOYTISOLO, J- Bms.: ¿Los denominados derechos fundamentales son derechos o son principios jurídicos? Una cuestión lingüística con secuencias jurídicas, Anales de la Real Academia de Jurisprudencia y Legislación, número 36, pág., 13 a 31, Madrid, 2006.

\section{La autora}

Cristina Fuertes-Planas Aleix. Licenciada en Derecho (UCM) 1986. Doctora en Derecho: 1992, sobresaliente cum laude y Premio Extraordinario. Profesora de Derecho Canónico y Eclesiástico en el C. U. Cardenal Cisneros desde 1986 hasta 2006. Profesora de "Derecho" en la Facultad de Ciencias de la Información (UCM), Sección Departamental de Filosofía del derecho desde 1992. Secretaria de la Sección Departamental de Filosofía del Derecho en la Facultad de Ciencias de la Información (UCM) desde 1992.Académica Correspondiente de la Real Academia y Jurisprudencia desde 2004. Coordinadora de la Sección de Filosofía del Derecho en la Real Academia de jurisprudencia y Legislación. Diploma de Práctica jurídica de un año de duración (UCM), 1987. Diploma en Estudios teóricos y prácticos de Hacienda Pública y Derecho Tributario Español, CETE, 2 años de duración, 1987 a 1989. Diploma de Derecho de Familia de un año de duración (UCM), 2006. 